\title{
Human-wildlife Conflicts in Ethiopian Protected Areas
}

\author{
*Getahun Shanko Bekele Tona \\ Department of Natural Resource Management, Wolaita Sodo University Dawro Tarcha Campus, \\ P. O. Box 01, Tarcha, Ethiopia
}

\begin{abstract}
The paper aimed to review Human-Wildlife Conflict which is fast becoming a serious threat to the survival of many endangered species in the world. Thus, this paper seeks to compile detailed information regarding the nature and magnitude of HWC and mitigation measures taken to reduce human-wildlife conflict in different protected areas in Ethiopia. A lot of literatures and reports from print and electronic media were consulted during the course of preparation of the article. The main problem that cause such conflict between wildlife the local community residing near the protected area of Ethiopia was created by lack of access to forest resources for the local community, crop and livestock damage on humans. Hyena and Baboon were common problematic animals in different protected areas of Ethiopia. To reduce such conflicts and promote sustainable conservation; comanagement and interdisciplinary participation of different sectors were needed.
\end{abstract}

Keywords: Guarding, Human-wildlife conflict, Protected area, Local community

DOI: $10.7176 / \mathrm{JRDM} / 65-04$

Publication date:May $31^{\text {st }} 2020$

\section{Introduction}

Protected areas for a long time have been the most effective and widely used as a measure for conserving nature and natural resources. It is estimated that in virtually in all countries, over five percent of the earth's land surface has been allocated for conservation purposes. These areas are important tourist attractions, watershed protection, national identity points, and conserve biological diversity (Jeffrey 1996).

Currently, there are over 147,000 protected areas in the world, covering the total area of 19.3 million $\mathrm{km} 2$, which is $13 \%$ of Earth's total land area, or approximately the size of the entire African continent. In contrast, only $0.8 \%$ of the global ocean area constitutes protected marine areas (Danijela, 2016).

Protected areas are created throughout the world to conserve biological diversity, protect critical watersheds, prevent overexploitation of forest resources, and preserve scenic natural areas. In Africa, the need to conserve wild- life whose numbers were drastically declining due to increased hunting, led to the establishment of formally protected areas starting early in the twentieth century (Teferra and Beyene, 2014). Such conservation policy was introduced by colonial powers and later on expanded by the conservation experts. Nevertheless, their establishment overlooked the livelihood bases of local people, and the gazetting of national parks is in a direct conflict with local people's livelihoods. These conflicts have challenged practitioners to seek new methods for reconciling the tradeoffs between national conservation policies and local people's demand to sustain livelihoods (Reddy and Workneh, 2014). However, over a long period of time protected areas have become the perfect niche for conflict between man and wildlife.

Human-Wildlife Conflict (HWC) is regarded as any interaction between humans and wildlife that results in negative impacts on social, economic or cultural life, on the conservation of wildlife populations, or on the environment. Conflicts between people and wildlife have been widely recognized as one of the most challenging issues for wildlife conservation worldwide (IUCN, 2010).

Human-wildlife conflict (HWC) is common where wildlife and human populations coexist and share limited resources and has become a considerable problem throughout the world (Schwerdtner and Bernd 2007). It occur when either the need or behavior of wildlife impact negatively on human livelihoods or when the humans pursue goals that impact negatively on the needs of wildlife. The continuous increase in the human population results in competition between people and wildlife for shared but limited resources, which manifest as various types of conflict, such as crop-raiding, livestock depredation, property damage, human injury and death, and the retaliatory killing of wildlife.

Human-wildlife conflicts have been in existence as long as wild animals and people shared the same resources. Sharing and completion for limited resources will leads to HWC. Crop-riding by wild animals is a common problem all over the world. This conflict is worsening in areas where humans and wild animal's requirements overlap (Gandiwa et al., 2012). The conflict is occurring everywhere in the world. Although, the problem of HWC is exist everywhere, the situation is more severe for Africa continent where majority of the people depends on agriculture, which accelerates the conversion of wild habitat to agricultural fields (Kate, 2012).

The objective of this paper is to review the nature and magnitude of $\mathrm{HWC}$ and mitigation measures taken to reduce human-wildlife conflict in different protected areas in Ethiopia. 


\section{Nature and magnitude of Human-wildlife Conflicts in Protected area of Ethiopia}

The types of conflicts were found to exist in the protected area of Ethiopia and adjoining community owned areas are either of the people and their livestock move into the protected area to access the resources that they need and lack in their areas or when wild animals disperse from the protected area into the community land either to feed on their crops or on their normal migrations to their feeding or breeding areas.

Local communities' encroachment to wildlife area to generate the requisite level of domestic animal product for support, the local communities graze the protected area by entering areas traditionally inhabited by wild animals. Though there is very large numbers of the local community live within the protected area, the local community encroaches onto the protected area, the native wildlife and humans are brought into conflict in Yabello Protected area (Tesfaye and Jatin, 2017). The local communities in different parts of Protected area uses the forest products to support their daily consumption and for marketing goods such as charcoal is another factor.

The study conducted by (Megaze et al, 2017) in South west Ethiopia namely Chebera churchura national park on the sample size of 354 respondents $61.5 \%$ claimed that problematic animals such as Papio Anubis, Syncerus caffer and Crocuta crocuta had recently increased in the area which is the major causes for human wild conflict. Increase in the number of wildlife populations and human proximity to the protected area is also common problem in in Borena Sayint National Park (Biset et al, 2019). The growing densities in livestock populations can create an overlap of diets and encourage competition with wild herbivores, resulting in overgrazing and a decline or even extinction in wild herbivore populations (Tesfaye and Jatin, 2017).

According to Tesfaye and Jatin (2017), wild animals that engage in crop raiding in his study area were monkeys, antelope, zebras, and wild pigs are the major wild contributors to crop damage. Many of these animals, such as the dik-diks, are also hunted by community members. Although some species are also disappearing, in recent years local wildlife offices have established committees for species that live in and around the Yabello protected area

Because of limited access to cash and lack of compensated for crop losses, the local communities of Ethiopia is more suffered by crop damaged by wild animals. Study conducted by (Mojo et al., 2014) in Checha district of Gurage Zones in Ethiopia, shows that grivet monkey is one of the major wild animals that frequently damage crops. Crop raiding undermines food security and tolerance of wildlife within neighboring human communities. The perception of respondents toward wildlife such as leopards being among the major problematic wildlife species could be due to its livestock depredation behavior and threatening human life. Leopards may cause a wide range of damages on human property and injure and kill humans. Leopards have been frequently cited among the top livestock predators wherever its range overlaps with livestock (Yirga et al. 2013).

Large carnivores like lions, spotted hyenas and leopards were reported to attack cattle, donkey's goats and sheep in Tanzania (Kissui, 2008). Other studies in Ethiopia by Yihune et al, (2009) indicated that spotted hyena caused the most pronounced problems and the local communities' loss their oxen, cows, donkeys, mules and horses by spotted hyena. In Chebera Churchura national park a total of 1449 predator attacks were reported during the study period. A total of 221 sheep (Ovis aries), 306 goats (Capra hircus), 206 cattle, 577 chickens (Gallus gallus domesticus), 36 donkeys (Equus africanus asinus) and $103 \mathrm{dogs}$ (Canis familiaris) were killed by predators (Biset et al, 2019). Hyenas are a cause for great concern, as they are pack animals; when they intrude on developing settlements in large numbers, they frequently cause significant damage. When native prey is abundant, wild predators tended to prefer it to livestock, and diminishing prey populations is one of the major causes of increased predatory tendencies in the animals (Tesfaye and Jatin, 2017).

According to Kebede et al (2016), Leopard and spotted hyena were reported to be the most destructive wild animal in all surveyed villages, including baboons, which were especially destructive in all villages further away from the protected area. Leopard Prefer cow for their prey. Hyenas were reported to be responsible for all types of livestock depredation, from cattle to poultry. Poultry were mainly depredated by small carnivores (jackals and baboons).

In many parts of Africa, the conflict between local people and wildlife is one of the most serious problems where villagers are located adjacent to nature reserves (Mackenzie 2012). The study conducted by Megaze et al (2017) in Chebera churcura national park revealed that living in close proximity like human settlements and agricultural fields to protected areas imposes costs such as loss of crops and livestock to wildlife, injury and death, and time and resources spent to guard livestock.

The local people of the present study area deployed various traditional methods to protect their crops and livestock from pest animals. They used repellents in the form of fire, noise and chemicals, and construction of different physical barriers, guarding, fear-provoking stimuli such as scarecrows, beating drums and chemical repellents for deterring crop-raiding wildlife. Capsaicin resin extracted from chilli peppers, which causes an extremely unpleasant irritation and burning, were used by local people as a chemical deterrent for a variety of wildlife species (Aberham, et al, 2017).

Local communities in different parts of protected area perceived that guarding where used with other methods is effective and had a low capital investment, but often is tedious and time consuming. The behaviour and 
preference of each of the pests are quite different (Datiko and Bekele, 2013).

Local communities identified several different methods that they traditionally used to control wildlife menace.

The methods included making noise using objects especially metal objects, scarecrows, burning of hot pepper, use of fire, burning of cow dung, use of dogs, use of spears, use of traps, burning of rubber and killing animals using arrows (Makindi, et al 2014).

As noted by Parker and Osborn (2006), alternative crops, such as ginger and chilli, have been encouraged. Beside the visible impacts, human-wildlife conflict has indirect impacts. Losses might generate other costs to the household members, including an increased need to guard fields, disruption of schooling because children are needed to help guard family fields and increased risk of injury from wildlife.

\section{Conclusion and Recommendation}

The review shown that there is intense conflict between wildlife and local people in different protected areas of Ethiopia. But the level, the cause and mitigation measure they used to reduce the conflict varied. Crop-riding by wild animals and livestock depredation were the major causes for the conflict. Traditionally, different method especially repellents and physical barriers like guarding were used to protect their livestock and crops. To reduce such problem community-based wildlife conservation in different area were recommended.

\section{References}

Aberham Megaze, Mundanthra Balakrishnan \& Gurja Belay (2017) Human-wildlife conflict and attitude of local people towards conservation of wildlife in Chebera Churchura National Park, Ethiopia, African Zoology, $52: 1,1-8$

Biset, A., Mengesha, G., and Girma Z (2019) Human-wildlife conflict in Ethiopia in and around Borena Sayint National Park, northern Ethiopia Human-Wildlife Interactions 13(1):111-124, Spring 2019

Danijela A., 2016. Evaluation of Protected Area Management Effectiveness - An Overview

Datiko, D., and A. Bekele. (2013). Conservation challenge: human-carnivore conflict in Chebera Churchura National Park, Ethiopia. Greener Journal of Biological Science 3:108-115.

Gandiwa, E; Heitkönig, LMA; Lokhorst, AM; Prins, HHT; Leeuwis, C (2013). CAMPFIRE and Human-Wildlife Conflicts in Local Communities Bordering Northern Gonarezhou National Park, Zimbabwe. Ecology and Society. 18 (4), 4.

International Union for Conservation of Nature (IUCN). 2010. Preventing and mitigating human-wildlife conflicts: WPC Recommendation V.20. International Union for Conservation of Nature, Gland, Switzerland,

Kate, K (2012). Possible Strategies or Practices in Reducing Wild animals (Primate) Crop raids in unprotected areas in Hoima District, Conducted in two Sub-Counties in Hoima District, A report to the PCLG-Uganda

Kebede, Y., Tekalign, W. and Menale,(2016) H., Conservation Challenge: Human-Carnivore Conflict in Sodo Community Managed Conservation Forest, Wolaita Sodo Zuriya District, Southern Ethiopia.

Kissui, B (2008). Livestock predation by lions, leopards, spotted hyenas and their vulnerability to retaliatory killing in the Maasai Steppe, Tanzania. Animal Conservation. 11 (5): 422-432.

Mackenzie CA. 2012. Accruing benefit or loss from a protected area: location matters. Ecological Economics 76 : 119-129.

Makindi, S.M., Mutinda, M.N., Olekaikai, N.K., Olelebo, W.L. and Aboud, A.A., (2014). Human-wildlife conflicts: causes and mitigation measures in Tsavo Conservation Area, Kenya.

Mojo, D; Rothschuh, J; Alebachew, M (2014). Farmers Perceptions of the Impacts of Human Wildlife Conflict on their Livelihood and Natural Resources Management Efforts in Cheha Woreda of Gurage Zone, Ethiopia. Human-wildlife interactions 8 (1): 67-77.

Parker GE, Osborn FV. 2006. Investigating the potential for chilli Capsicum spp. to reduce human-wildlife conflict in Zimbabwe. Oryx 40: 343-346.

Schwerdtner K, Bernd G. 2007. A conceptual framework for damage compensation scheme. Biol Conserv. 134: 354-360.

Teferra, F. \& Beyene, F., 2014. Indigenous claims and conflicts in managing the Abijata-Shalla Lakes National Park , Ethiopia. International Journal of Biodiversity Science, Ecosystem Services \& Management, 10(3), pp.216-227.

Tesfaye Fentaw \& Jatni Duba (2017) Human-Wildlife Conflict among the Pastoral Communities of Southern Rangelands of Ethiopia: The Case of Yabello Protected Area, Journal of International Wildlife Law \& Policy, 20:2, 198-206

White, P. C., and Ward, A. I. (2011). Interdisciplinary approaches for the management of existing and emerging human-wildlife conflicts. Wildl Res; 37: 623-629.

Yihune, M; Bekele, A; Tefera, Z (2009). HumanWildlife Conflict and around the Simien Mountains National Park, Ethiopia. SINET: Ethiopia. J. Sci. 32 (1): 57-64.

Yirga, G., H. H. Iongh, H. Leirs, G. Kindeya, B. Gebrehiwot, A. Tsehay, G. Haftu, and H. Bauer. 2013. The ecology of large carnivores in the highlands of northern Ethiopia. African Journal of Ecology 51:78-86. 